\title{
Information entropy analysis of seismicity of Umbria-Marche region (Central Italy)
}

\author{
L. Telesca, V. Lapenna, and M. Lovallo \\ Institute of Methodologies for Environmental Analysis, National Research Council, Tito, Italy \\ Received: 12 July 2004 - Revised: 26 October 2004 - Accepted: 1 November 2004 - Published: 3 November 2004 \\ Part of Special Issue "Precursory phenomena, seismic hazard evaluation and seismo-tectonic electromagnetic effects"
}

\begin{abstract}
We investigated by means of nonlinear tools the temporal distribution of 1983-2003 seismicity of the Umbria-Marche region, Central Italy, that was struck by a strong event $(\mathrm{M}=5.8)$ on 26 September 1997. Information entropy analysis has been performed over the full and the aftershock-depleted catalogue. We analysed the series of the interevent times between successive earthquakes and the series of their magnitudes. The time evolution of this measure shows a clear anomalous behaviour in correspondence with the stronger event, more evident in the full catalogue than in the aftershock-depleted one.
\end{abstract}

\section{Introduction}

Time series data, representing the measurement of some variables of interest, have been studied in order to extract information on the dynamics of underlying geophysical processes. Nonlinear time series tools have been extensively used to reveal the presence of underlying chaotic dynamics, whether the variables arise from a low dimensional attractor, whether this attractor has fractal dimension which can be inferred from time series data, etc. (Azad et al., 2002). In particular, seismicity data are well suited to be studied by means of several methodologies, in order to furnish a better understanding of tectonic processes. Seismicity in a more general sense is probably evidence of a variety of complex causes. Long term behaviour of seismicity appears random but it reflects integral characteristics of the lithosphere dynamics and encompasses all the complexities of faulting ( $\mathrm{Li}$ and Nyland, 1994). Several features of the lithosphere allow for a nonlinear description of seismicity data: i) interaction of the processes of different physical origin, and of different spatial and temporal scales; ii) hierarchical block or possibly fractal structures; iii) self-similarity in space, time and energy. The lithosphere of the Earth can be viewed as a hi-

Correspondence to: L. Telesca

(ltelesca@imaa.cnr.it) erachy of volumes, from tectonic plates to grains of rock. Their relative motion against the forces of friction and cohesion is realized to a large extent through earthquakes. The motion is controlled by a wide variety of independent processes, concentrated in the thin boundary zones between the volumes. A boundary zone has a similar hierarchical structure, consisting of volumes, separated by boundary zones, etc. Altogether, these processes transform the lithosphere into a large nonlinear system, featuring instability and deterministic chaos (Keilis-Borok, 1990). The presence of a large amount of different nonlinear mechanisms important for the seismotectonic process suggests the applicability of the genral approach of nonlinear science to complex dissipative systems as shown by earthquake sequences.

In this paper we analyzed the earthquake sequence from 1983 to 2003 in the Umbria-Marche region, central Italy, by means of information entropy to qualify and quantify dynamical patterns.

\section{Tectonic settings}

The Umbria-Marche region, central Italy, has been subjected to a great scientific interest, after the strong 26 September 1997 seismic event $\left(\mathbf{M}_{S}=5.9\right)$ that struck the area, and many studies have been performed regarding its geodynamical features (Boncio and Lavecchia, 2000; Calamita et al., 2000; Vittori et al., 2000), active tectonics (Galadini et al., 1999; Cinti et al., 2000; Morelli et al., 2000), spatio-temporal seismic distribution (Ripepe et al., 2000; Di Giovambattista and Tyupkin, 2000; Deschamps et al., 2000; Cattaneo et al., 2000), induced geophysical effects (Quattrocchi et al., 2000; Esposito et al., 2000).

The central Apennines are made up of several tectonic units put straight since the Oligocene as a results of convergence and collision between the continental margins of the Corsica-Sardinia block and the Adriatic block (Cello et al., 1995). The main compressive phase started in the Tortonian and the lack of Pliocene-Pleistocene marine deposits 


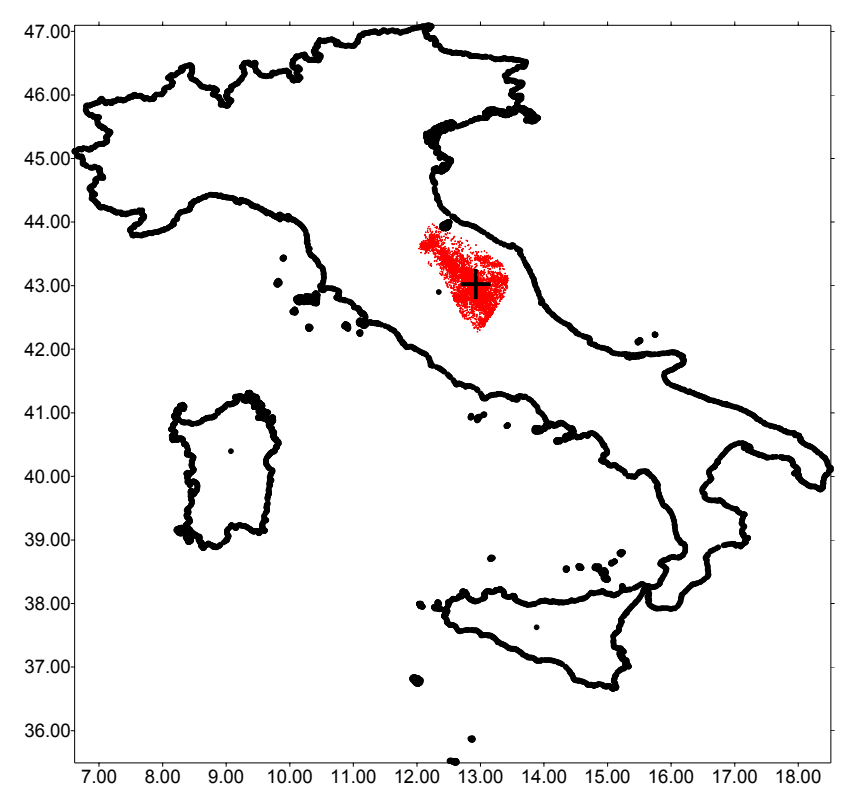

Fig. 1. Map of the Umbria-Marche region (central Italy). The cross indicates the stronger event $(M=5.8)$ in the area.

prove that after the Miocene the area was definitively uplifted. The compressive structures were dissected by normal faults during the Quaternary, and, according to the most recent studies (Calamita et al., 1994; Lavecchia et al., 1994), these are related to the crustal thinning processes occurring in the Tyrrhenian Tuscan area. The Quaternary normal faults led to the formation of intramountain basins, and the seismicity of the area is mainly related to the activity of these faults. The Umbria-Marche region is part of the east-verging Neogene thrust and fold belt of Central Italy (Bally et al., 1988; Patacca et al., 1992; Calamita et al., 1994). Middle-late Quaternary faults and intermontane tectonic depressions, overprinted onto the thrust structure, are the preferential loci of strong to moderate earthquakes, as shown by historical and instrumental data and geological evidence (Cello et al., 1997; Vittori et al., 1997; Vittori et al., 2000).

The Umbria-Marche region is characterized by a welldocumented historical and instrumental seismicity, mainly confined within the upper part of the crust $(<16 \mathrm{~km})$ (Lavecchia et al., 1994). West of the Tiber Basin, the seismic activity is the lowest. It increases remarkably within the Apennine area, where small to moderate $(4<M<6)$ earthquakes are frequent, while largest earthquakes $(6<\mathrm{M}<7)$ have long recurrence-intervals (Boncio and Lavecchia, 2000). Four highly damaging earthquakes (1279 Camerino, 1328 Norcia, 1703 Norcia and 1751 Gualdo Tadino) have occurred in the last centuries within the Città di Castello-Gubbio-Gualdo Tadino-Norcia seismic band. In the same area the largest instrumental earthquakes of the last twenty years (M5.9 1979 Norcia, M5.2 1984 Gubbio, M5.9 1997 Colfiorito) are located (Boncio and Lavecchia, 2000).

The analysed earthquake data were extracted by the National Institute of Geophysics and Volcanology instru- mental catalogue (INGV), available on the internet site at http://www.ingv.it, and cover the period 1983-2003. Figure 1 shows the epicenter distribution of the earthquakes, analysed in this paper.

\section{Data analysis}

We analyzed the full and the aftershock-depleted catalogues. We depleted the catalogue by means of the method of Reasenberg (1985), which is physically based and considers each earthquake capable to generate an alteration of the surrounding stress field that may trigger a further seismic event, which nucleates in its surroundings a modified stress field. The areal and time extent for which the event can trigger a following event is called interaction zone of the earthquake, whose length scale is proportional to the source dimension, and the temporal scale is determined with a probabilistic model based on Omori's law. Thus, we applied the Reasenberg's algorithm to remove aftershocks from the Umbria-Marche catalogue.

Figure 1 shows the area investigated and the spatial distribution of the epicenters of the earthquakes extracted by the instrumental catalogue of the Institute of Geophysics and Volcanology (INGV). We firstly performed the analysis of Gutenberg-Richter (1944) to obtain the minimum magnitude from which the catalogue could be considered complete: the full catalogue is complete for events with magnitude $M \geq 2.4$ $(\mathrm{N}=5988)$.

The aim of the present paper is the analysis of the time dynamics of Umbria-Marche seismicity by means of information entropy measure, applied on both interevent and magnitude time series.

The information entropy $H$ is given by the well-known equation of Shannon (Kolmogorov, 1965):

$H=-\sum_{k=1}^{n} P_{k} \log \left(P_{k}\right)$,

where $P_{k}$ is the probability of the state $k$, and it reaches its maximum value if all states are equiprobable, that is when $P_{k}=1 / n$, for $k=1,2, \cdots, n$; in this case, we have no indication whatsoever to assume that one state is more probable than another state. The information entropy $H$ expresses our uncertainty or ignorance about the system's state. It is clear that $H=0$, if and only if the probability of a certain state is 1 (and of all other states 0 ), $P_{k}=1$ for some $k$ and $P_{h}=0$ for $h \neq k$. In that case we have maximal certainty or complete information about what state the system is in. Uncertainty also relates to the concept of predictability. When something is completely predictable, it is completely certain, and it contains very little, if any, information. Entropy refers to the degree of randomness, lack of organization, or disorder in a situation. Therefore, the information entropy furnishes the information about (i) the deviation from the equiprobable state, characterized by a uniform distribution, and (ii) the degree of "order" of a system. 


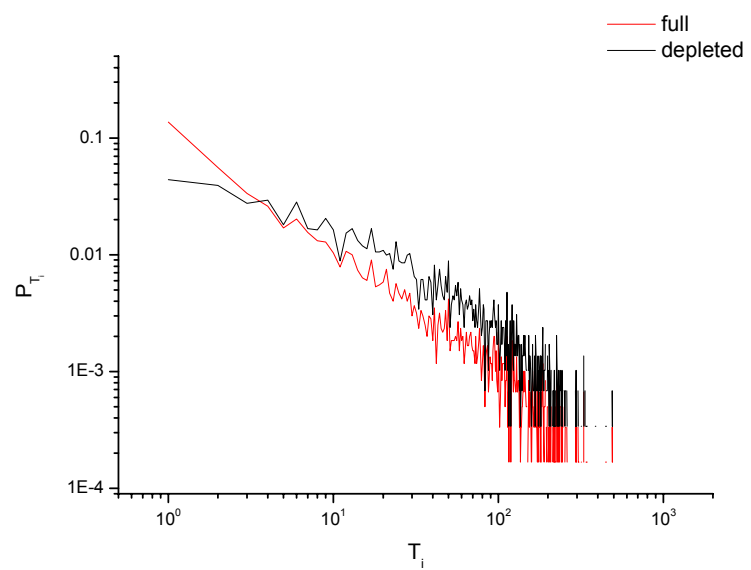

(a)

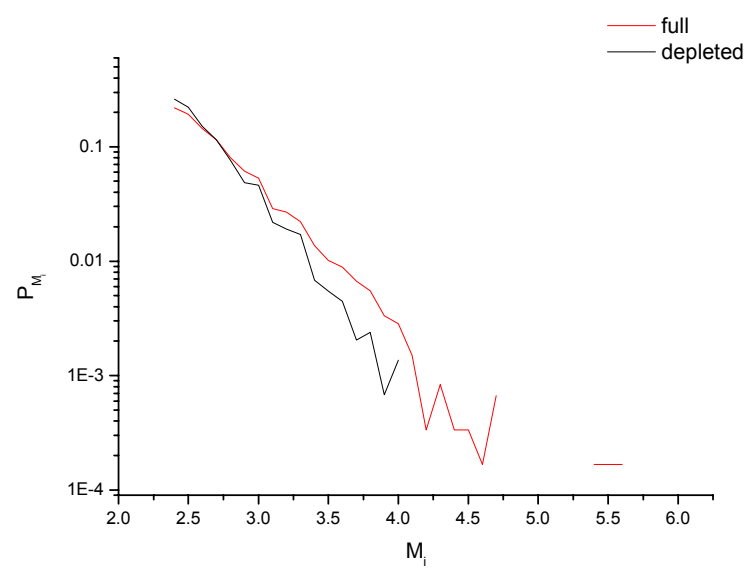

(b)

Fig. 2. Histograms of the interevent times (a) and magnitudes (b).

To calculate this quantity we need to compute the histogram, which is an approximation of the probability density function. Depending on the time structure of the variable, continuous (as the interevent times) or discrete (as the magnitudes), we will use different, but equivalent, definition of histogram. Let us consider the statistical sample by $\left\{s_{i}\right\}_{i=1}^{N}$, where $N$ is the length of the sample. If $s_{i}$ is a continuous variable: (i) we consider a finite interval $(a, b)$ such that $a \leq \min _{i}\left\{s_{i}\right\}$ and $b \geq \max _{i}\left\{s_{i}\right\}$; (ii) we divide the interval (a, b) into $\mathrm{n}$ nonintersecting subintervals of equal length $L=(\mathrm{b}$ a) $/ n$; (iii) then the probability $P_{k}$ of the subinterval $\left(x_{k}, x_{k+1}\right)$ is given by

$P_{k}(x)=\frac{\#\left\{s_{i} \in\left[x_{k}, x_{k+1}\right): x \in\left[x_{k}, x_{k+1}\right),\right\}}{N}$,

where the symbol \# indicates the number of elements in the set.

If $\mathrm{s}_{i}$ is a discrete variable, we deal with a process with $\mathrm{n}$ possible discrete outcomes, and the probability associated to the specified outcome $\mathrm{s}_{i}$ is simply

$P_{i}=\frac{\#\left\{s_{i}\right\}}{N}$.

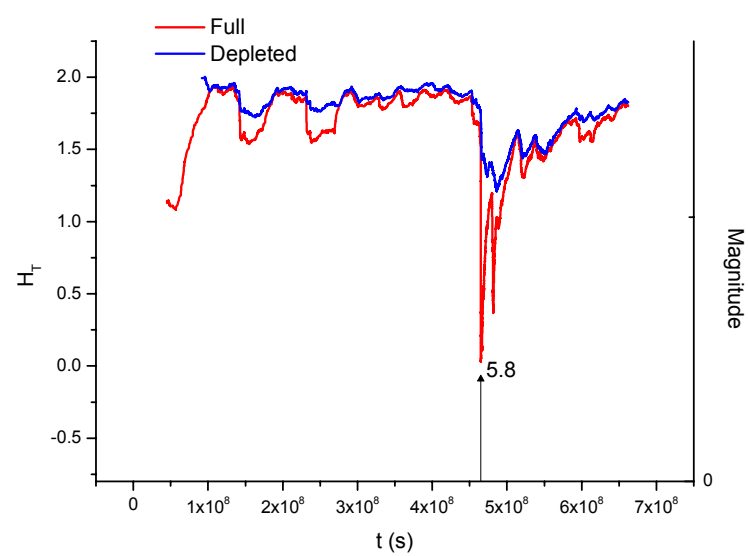

(a)

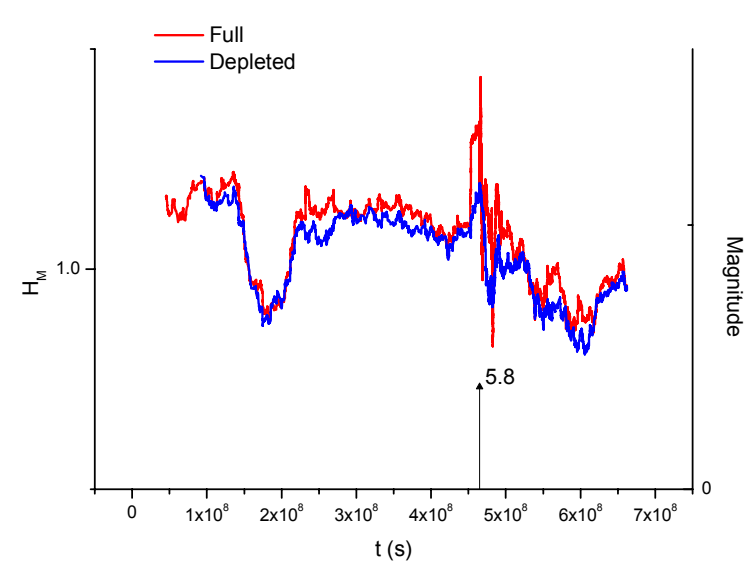

(b)

Fig. 3. Time variation of the information entropy for the interevent intervals $\left(H_{T}\right)$ and the magnitudes $\left(H_{M}\right)$. The vertical arrow indicates the occurrence time of the principal mainshock of the sequence.

We calculated the information entropy for the interevent times using Eq. (2) and that for the magnitudes using Eq. (3). Regarding the interevent time series, we chose the parameter $L=1 \mathrm{~h}$, and the histograms of the full and depleted series are shown in Fig. 2a. We obtained $H_{T}=1.5266$ in the full case and $H_{T}=2.1284$ in the depleted case. We see that the information entropy in the depleted case is slightly larger than that obtained in the full case, because the deletion of the aftershocks, which introduce short interevent times, has made the catalogue more uniform than the full catalogue. Figure $2 b$ shows the probability distribution of the magnitudes in the full and aftershock-depleted case. The estimated value of the information entropy for the magnitudes is $H_{M}=0.9877$ in the full case and $H_{M}=0.8955$ in the depleted case. The values are very close to each other, because the deletion of the aftershocks has not changed dramatically the magnitude distribution.

We analyze now the time variation of the information entropies $H_{T}$ and $H_{M}$ calculated using the full as well as the 
aftershock-depleted catalog. Figure 3 shows the results. It is clear the strong change of both parameters, especially in the full catalog, concomitantly with the occurrence of the largest shock of magnitude 5.8 on 26 September 1997. The $H_{T}$ sharply decreases to 0 and $\sim 1.2$ in the full and aftershockdepleted case respectively. Although the decreasing behavior is visible in both sequences, it is more evident in the full series. The tendency of $H_{T}$ of the full sequence downward zero indicates a loss of information, due to the increased probability of estimation of the interevent intervals after the mainschock. In opposition, the behaviour of $H_{M}$, which increases during the occurrence of the aftershocks, indicating that the magnitudes are less predictable and tend to be uniformly distributed.

\section{Conclusions}

In the present study we performed a nonlinear analysis of the 1983-2003 Umbria-Marche region (central Italy) seismicity. The information entropy analysis performed over the full as well as the aftershock-depleted catalogs has revealed the following features: i) the Umbria-Marche seismic process, described by the interevent interval and magnitude time series, is characterized by nonlinear dynamics, quantified by the information entropy of the interevent intervals $H_{T}$ and magnitudes $H_{M}$; ii) these two parameters are able to quantify the degree of randomness or the degree of predictability of the interevent time or magnitude of a sequence of earthquakes; (iii) the time variation of both paramaters has revealed opposite behaviors, but anomalous change in correspondence with the largest shock in the sequence is evident in both quantities; (iv) $H_{T}(t)$ has suggested that the predictability of interevent times of the aftershocks increases, because of the large frequency of small interevent intervals; while $H_{M}(t)$ has revealed that the predictability of the magnitudes decreases.

Edited by: M. Contadakis

Reviewed by: F. Vallianatos and another referee

\section{References}

Azad, R. K., Rao, J. S., and Ramaswamy, R.: Information-entropic analysis of chaotic time series: determination of time-delays and dynamical coupling, Chaos Solitons \& Fractals, 14, 633-641, 2002.

Bally, A. W., Burbi, L., Cooper, C., and Ghelardoni, R.: Balanced sections and seismic reflection profiles across the Central Apennines, Mem. Soc. Geol. It., 35, 257-310, 1988.

Boncio, P. and Lavecchia, G.: A structural model for active extension in Central Italy, J. Geodynamics, 29, 233-244, 2000.

Calamita, F., Coltorti, M., Piccinini, D., Pierantoni, P. P., Pizzi, A., Ripepe, M., Scisciani, V., and Turco, E.: Quaternary faults and seismicity in the Umbria-Marchean Apennines (central Italy): evidences from the 1997 Colfiorito earthquake, J. Geodynamics, 29, 245-264, 2000.
Calamita, F., Cello, G., Deiana, G., and Paltrinieri, W.: Structural styles, chronology-rates of deformation and time space relationships in the Umbria-Marche thrust system (Central Apennines, Italy), Tectonics, 13, 873-881, 1004.

Cattaneo, M., Augliera, P., De Luca, G., Gorini, A., Govoni, A., Marcucci, S., Michelini, A., Monachesi, G., Spallarossa, D., Trojani, L., and XGUMS: The 1997 Umbria-Marche (Italy) earthquake sequence: analysis of the data recorded by the local and temporary networks, J. Seismology, 4, 401-414, 2000.

Cello, G., Mazzoli, S., Tondi, E., and Turco, E.: Active tectonics in the Central Apennines and possible implications for seismic hazard analysis in peninsular Italy, Tectonophysics, 272, 43-68, 1997.

Cello, G., Turco, E., and Zuppetta, A.: Cinematica del settore centrale del Mediterraneo ed implicazioni sulla struttura dell'arco calabro. In Bonardi G., De Vivo, B., Gasparini, P., and Vallario, A. (eds), Cinquant'anni di attività didattica del Prof. F. Ippolito, Napoli, Liguori Editore, 293, 1995.

Cinti, F. R., Cucci, L., Marra, F., and Montone, P.: The 1997 Umbria-Marche earthquakes (Italy): relation between the surface tectonic breaks and the area of deformation, J. Seismology, 4, 333-343, 2000.

Deschamps, A., Courboulex, F., Gaffet, S., Lomax, A., Virieux, J., Amato, A., Azzara, A., Castello, B., Chiarabba, C., Cimini, G. B., Cocco, M., Di Bona, M., Margheriti, L., Mele, F., Selvaggi, G., Chiaraluce, L., Piccinini, D., and Ripepe, M.: Spatiotemporal distribution of seismic activity during the UmbriaMarche crisis, 1997, J. Seismology, 4, 377-386, 2000.

Di Giovambattista, R. and Tyupkin, Y. S.: Spatial and temporal distribution of seismicity before the Umbria-Marche 26 September 1997 earthquakes, J. Seismology, 4, 589-598, 2000.

Esposito, E., Porfido, S., Simonelli, A. L., Mastrolorenzo, G., and Iaccarino, G.: Landslides and other surface effects induced by the 1997 Umbria-Marche seismic sequence, Eng. Geology, 58, 353-376, 2000.

Galadini, F., Galli, P., Leschiutta, I., Monachesi, G., and Stucchi, M.: Active tectonics and seismicity in the area of the 1997 earthquake sequence in central Italy: A short review, J. Seismology, 3, 167-175, 1999.

Gutenberg, B. and Richter, C. F.: Frequency of earthquakes in California, Bull. Seism. Soc. Am., 34, 185-188, 1944.

Keilis-Borok, V. I.: The lithosphere of the Earth as a nonlinear system with implications for earthquake prediction, Rev. Geophys., 28, 19-34, 1990.

Kolmogorov, A. N.: Three approaches to the quantitative definition of information, Problems Inform. Transmission, 1, 1-7, 1965.

Lavecchia, G., Brozzetti, F., Barchi, M., Menichetti, M., and Keller, J. V. A.: Seismotectoning zoning in east-central Italy deduced from an analysis from the Neogene to present deformations and related stress fields, Geol. Soc. Am. Bull., 106, 1107-1120, 1994.

Li, Q. and Nyland, E.: Is the dynamics of the litosphere chaotic?, in Nonlinear Dynamics and Predictability of Geophysical Phenomena, edited by Newman, W. I., Gabrielov, A., and Turcotte, D. L., Geophysical Monograph 83, IUGG 18, 37-41, 1994.

Morelli, A., Ekström, G., and Olivieri, M.: Source properties of the 1997-98 Central Italy earthquake sequence from inversion of long-period and broad-band seismograms, J. Seismology, 4, 365-375, 2000.

Patacca, E., Sartori, R., and Scandone, P.: Tyrrhenian basin and Apennine arcs: kinematics relations since late Tortonian times, Mem. Soc. Geol. It, 3, 1-8, 1992. 
Quattrocchi, F., Pik, R., Pizzino, L., Guerra, M., Scarlato, P., Angelone, M., Barbieri, M., Conti, A., Marty, B., Sacchi, E., Zuppi, G. M., and Lombardi, S.: Geochemical changes at the Bagni di Triponzo thermal spring during the Umbria-Marche 1997-1998 seismic sequence, J. Seismology, 4, 567-587, 2000.

Ripepe, M., Piccinini, D., and Chiaraluce, L.: Foreshock sequence of the 26 September 1997 Umbria-Marche earthquakes, J. Seismology, 4, 387-399, 2000.

Reasenberg, P.: Second-order moment of central California seismicity, 1969-1982, J. Geophys. Res., 90, 5479-5495, 1985.
Vittori, E., Maschio, L., Ferreli, L., Michetti, A. M., and Serva, L.: Carta e base di dati delle faglie capaci per l'Italia centromeridionale: presentazione e stato di avanzamento del progetto ITHACA, Il Quaternario, 10, 2, 305-321, 1997.

Vittori, E., Deiana, G., Esposito, E., Ferreli, L., Marchegiani, L., Mastrolorenzo, G., Michetti, A. M., Porfido, S., Serva, L., Simonelli, A.L., and Tondi, E.: Ground effects and surface faulting in the September-October 1997 Umbria-Marche (Central Italy) seismic sequence, J. Geodynamics, 29, 535-564, 2000. 